\title{
How to Retain a Bank Customer: A Qualitative Study of Jordanian Banks Relational Strategies
}

\author{
Muhammed S. Alnsour ${ }^{1}$ \\ ${ }^{1}$ Faculty of planning and management, Al-Balqa Applied University, Al-Salt, Jordan \\ Correspondence: Muhammed S. Alnsour, Faculty of planning and management, Al-Balqa Applied University, P. \\ O. Box Al-Salt 19117, Al-Salt, Jordan. Tel: 962-5-349-1111. E-mail: m.s.alnsour@bau.edu.jo
}

Received: March 24, 2013

Accepted: April 27, 2013 Online Published: May 27, 2013

doi:10.5539/ijms.v5n4p123

URL: http://dx.doi.org/10.5539/ijms.v5n4p123

\begin{abstract}
This paper studies how banks in Jordan promote long-term strategies in an effort to attract and retain loyal customers. An exploratory qualitative study was undertaken in order to develop a clearer understanding of background issues relating to the research problem. An in-depth interviewing technique was used, experts from nine different Jordanian banks participated in the data collection, the interviewees consisted of marketing directors, managers and executives as well as senior relationship managers and direct banking managers. Content analysis was used to analyze textual information from interviews in order to draw conclusions from them. Findings revealed Relational strategies, tactics, and tools used to achieve customer retention used by banks and benefits of customer retention, it also showed how retention is linked with customer profitability, findings showed that internal marketing is important for achieving retention. A number of drivers were found to be critical in banks efforts toward fulfilling relational strategies; trust, satisfaction, loyalty, commitment, closeness, communication, transparency, confidentiality, privacy, culture, customer acquisition, and reputation. However this study should be carried out in a different context. Further study is needed to explain how these constructs are linked in order to develop a model of customer retention.
\end{abstract}

Keywords: relationship marketing, customer retention, banking sector, Jordan

\section{Introduction}

In an industry that is characterised by intensive competition; Jordanian banks are struggling to keep their customer. This paper studies how banks in Jordan promote long-term strategies in an effort to attract and retain loyal customers. Banks are trying to reduce costly customer defections through applying relational strategies aiming at continuing patronage with their customers due to the positive effects that can result from customer retention.

\section{Jordanian Banking Industry}

Jordanian banking system is relatively small. Nevertheless, the Jordanian banking industry is one of the fastest growing industries in the Middle-East. A free market economic policy led to the emergence of diverse types of banks competing freely in the market. The Jordanian banking sector is important to the local economy, contributing an estimated 20\% to the Jordanian GDP (Dwairi et al., 2007). This booming industry has developed markedly in terms of electronic services and operations, information technology and communications that led to the introduction of new banking services.

All of this is reflected on the financial performance of many Jordanian banks that moved up in the list of top banks and financial institutions in the Middle East region (ASSOCIATION OF BANKS IN JORDAN, 2009). The banking sector is one of the most important sectors in the Jordanian economy. Privately owned banks provide capital for industry, construction, and trade. The banks are also the most heavily traded securities on the Amman Financial Market (Al-Shammari and Salimi, 1998).

The Jordan government is helping banks to supply adequate credit to businesses and consumers at reasonable and competitive prices. However, lending is quiet in Jordan (Siam, 2007). Banks in Jordan are learning to become conservative in their lending due to past experiences of other banks that have become bankrupt, this may positively affect the banks tendency towards the development of relational strategies aimed at achieving customer retention. Therefore, studies about Jordanian banking industry are important from the view point of 
investors, creditors, researcher and the government.

\section{Literature Review}

Recent environmental changes, especially the rapid growth of competition and the changing consumer landscape, increased customer choice. Due to these changes businesses have witnessed a strategic move away from "offensive marketing" aimed mostly at getting new customers to "defensive marketing" focused on customer retention (Lee-Kelley et al., 2002).

Many studies emphasize the benefits of customer retention in improving firm value and ultimately increases a firm's profits (Hidalgo et al., 2008) . hence, for managers to compete successfully in today's marketplace/space; it is a top priority for managers to develop a sound and profitable customer retention strategy (Weinstein, 2002).

Customer retention is a critical factor in achieving customer satisfaction (Danesh et al., 2012). It is an effective tool that banks can use to gain a strategic advantage and survive in today's banking competitive environment (Pal, 2011). Keeping the customer has become regarded as equally as, if not more important, than creating a new customer. There is a growing recognition that customers can be managed overtime since they have a life-cycle were they are acquired, retained and can be grown in value (Ang and Buttle, 2006).

Customer retention can be viewed as a measure of relationship continuation. It is a result of a kind of repetitive behavior ultimately aims at achieving customer loyalty (Liu and $\mathrm{Wu}, 2007$ ). Most bank product developments are easily imitated and they provide nearly identical services. Therefore, customer retention is potentially an effective tool that banks can use to gain a strategic advantage and survive in this highly competitive industry (Cohen et al., 2007).

Customer retention involves a focus on existing customers with an intention to develop a long-term relationships with them which will lead to the generation of further business (Harrison and Ansell, 2002). According to Ang and Buttle (2006) focusing on customer retention can yield several economic benefits; the longer customers stay with the firm, the repeated patronage results in increase in the volumes purchased, customer referrals will increase as well. Concurrently, customer and supplier learn more about each other which will result in relationship maintenance costs to fall. Customer replacement costs will fall also because fewer customers churn. All of these conditions increase the net present value of retained customers.

This paper is interested in answering a number of questions related to customer retention. What are the relationships between the variables of customer satisfaction, customer retention, and customer loyalty? But what are the elements that contribute to retaining customers, achieving satisfaction, and creating loyalty? How does customer loyalty differ from customer retention? Are all repeat customers loyal to the firm?

\section{Research Methodology}

This section explains the research methodology. It reports the methods used in this research. The interviews were coded manually by subdividing the data into categories, each of these categorise answers a question, explores the research context or gives an insight about the research problem, codes were attached to phrases, sentences or whole paragraphs in the interviews manuscripts, content analysis of qualitative data seeks to reduce the data into manageable categories and highlight main parts that will help in drawing conclusions.

The qualitative information provides new insights into the behaviours and attitudes of Jordanian banks toward developing relational strategies aimed at achieving customer retention. The interviews helped in understanding the drivers that captures strategies adapted by Jordanian banks aimed at achieving customer retention. Qualitative research is used to help explore the topic in depth with experts who happen to have an in depth knowledge in the field. Qualitative research allows for flexibility in gathering information. Interviews were conducted with key employees in nine different Jordanian banks.

\subsection{Qualitative Methodology}

An exploratory qualitative study was undertaken in order to develop a clearer understanding of background issues relating to the research problem as well as. Exploratory studies are performed to clarify ambiguity. Further, exploratory studies are useful in obtaining a good understanding of the research problem and advancing knowledge through good theory building; and generating hypotheses. Exploratory research has a flexible design that attempts to understand what is happening, seeks new insights, asks questions, shed new lights, and generates ideas and hypotheses for future research.

Qualitative methods cover a wide selection of interpretive techniques that seek to describe, decode, translate, and understand the meaning, not the frequency, of certain phenomena in the social world. In qualitative research the researcher needs to attempt to reduce the distance between theory and data and between context and action. 
Qualitative methods represent a mixture of the rational, unanticipated and intuition in which the personal experiences of the researcher are often inputs that should be understood and analyzed as data. Different business disciplines have commonly used qualitative research, as the primary, indeed sole, basis for study and data collection, and for clarification of research findings.

In an early exploratory stage of research qualitative methods help the researcher to understand the topic due to their open-ended, undetermined nature which allows the researcher to explore the field. During the development of the research design qualitative methods provide a relatively flexible plan of action that evolves with the increased knowledge. Throughout the study qualitative methods aid the understanding of the whole context and provide an open, flexible, practical and helpful way to study complexity.

As mentioned earlier, theory generation is often associated with qualitative research. Thus, the use of qualitative methodology in the first stage of the research can be justified based on the nature of the data to be collected and the goal of collecting such data. It is a theory building stage that requires the generation of an extensive amount of knowledge which is both important by itself and is needed for empirical testing during the second stage. The following sections will discuss how the interviews were planned, conducted, and interpreted as well as qualitative data collection and analysis, interviewing process.

\subsection{The Interviews}

Interviews can provide high quality data, but they can be time consuming. An in-depth interviewing technique that uses a structured process for analyzing data was used. Interviewing is suitable for exploratory, inductive research. Interviews can be extremely precious when the researcher is in some doubt about the information to be collected. A series of in-depth interviews were carried out with experts in Jordanian banks. Some of the issues raised in previous interviews were discussed in later ones in order to reach agreements between the interviewees, or to explain the disagreements between them.

\subsection{Interviewing Process}

All Jordanian banks were contacted. Some of the banks replied positively and showed their interest in cooperating. Appointments were made with the banks. An indicative list of the questions was given to each respondent to establish a common understanding of the issues to be discussed and the kind of information required for this research. People from nine different banks were interviewed. The people interviewed were marketing directors, relationship managers and account managers. The diversity of the respondents resulted in varied responses and helped in achieving a more rounded understanding of the issues.

\subsection{Data Analysis}

Qualitative data are interpreted qualitatively in this research using content analysis. In content analysis, the researcher classifies the key ideas in a transcribed interview by analyzing words. Content analysis is a systematic research method for analyzing textual information in a standardized way that allows making conclusions about that information. It classifies textual information into much fewer content categories.

The data were collected using in-depth interviewing. The interviews were transcribed and then analyzed using content analysis. The content analysis approach comprises a number of steps: identifying content; coding the data; categorizing the data; classifying respondents' opinions; comparing responses under each category and concluding.

\section{Findings}

\section{Relational strategies, tactics, and tools used to achieve customer retention}

Some respondents stressed the role of loyalty scheme programmes and how these can achieve loyalty. Also customized services were stressed as playing an important role in achieving customer retention.

"Loyalty scheme programmes can have a positive impact on certain customers. Customized services can also enhance and play a great role in enhancing customer perceptions about the bank and can keep customers interested in staying with the bank."

Quality of service was emphasized as being a way in achieving retention.

"Exceeding the expectations of the customers by excelling in quality and truly understanding their needs is capable of keeping customers."

"Customer retention can be achieved through continuous modernization of services this can be achieved by understanding the feedback that comes from customers and customer service people."

The key in excelling in quality according to the respondents is the deep understanding of the needs of the 
customers and offering a customized service that reflects this understanding.

A number of the respondents highlighted the role of continuous contact and two-way communication in achieving a common understanding which will result in customer satisfaction.

"Stressed the importance of using various communications through adapting technological advancements in banking as promoting the development of strong bonding between the bank and its employees".

"The secret is how to clearly communicate with customers and connect with employees at all levels."

One of the most important strategies mentioned by the respondents is related to developing the internal customers (human resources) through emphasizing the important role of internal marketing.

"In order to develop relational strategies, banks should in one hand improve human recourse skills and abilities to deal with customers, on the other hand technology can enhance communications and keep customers attached to the bank all time, availability of 24/7 communications is essential to gain customer and use that technology to serve those customer"

"The key to retain customers is to achieve customer satisfaction; satisfaction is gained through developing employees skills in how to deal with customer complaints and to deal with angry or unsatisfied customers."

To enhance the employees abilities, the banks internal climate should be enhanced.

"Taking care of the bank employees will promote a climate of comfort and understanding and will be reflected in the employees performance and the way they deal with the customers."

"The front line employees in each and every branch are the ones who are responsible for the direct contact with the customers, the banks adapts a philosophy of speed, easiness and efficiency in customer service. These service providers constitute a large portion of the banks image and have a direct effect convincing customers to make business with them and to retain them for a long time."

"Developing trust and making customers feel that they are confident in putting their money in the right place (capable, trusting and caring hands) is the way to keep Jordanian customers. These all can contribute and enhance to the image of the bank"

This will promote a culture of customer consciousness that protects customer confidentiality.

"Customer confidentiality is extremely critical in banking industry the way to achieve customer satisfaction is to ensure customer privacy. Privacy should be secured both online and offline. Technology can make our job more efficient through enhancing the availability of customers' interaction."

In order to stay competitive banks compare themselves with other banks in the industry.

"The bank emphasizes the role of benchmarking as an important source of competitiveness. Our bank compares and contrasts its interest rates, marketing efforts and relative position to other competitor banks in Jordan."

\section{Benefits of customer retention}

The respondents mentioned a number of benefits that a bank can get from retaining customers for a long while, these include:

"One of the greatest benefits of customer retention is building the bank's customer base, customer base is critical for achieving market growth and market share."

"Keeping the bank's customer base for a long time helps the bank in future planning and enhancing the competitive position of the bank."

"Keeping the customers for along time can build mutual trust between the bank and its client; this trust will encourage many of our customers to recommend the bank to their friends and relatives which ultimately will positively impact the bank profits".

"Retaining and keeping customers for a long while have a direct effect on satisfaction and loyalty and will keep the bank's customer base and is ultimately reflected in increased profitability".

"Banks survival is dependent on forming a strong customer base and maintaining the bank's market share which will lead to a steady stream of profits necessary for the bank's future growth."

"Improved relations with customers and using these relations to acquired new customers through customers is a great benefit of customer retention."

"Positive word of mouth is probably one of the most important virtues of customer retention, assuming that these customers are happy with the quality of service provided." 
"Retained customers who are satisfied have another positive effect; they are a source of free advertising through spreading constructive word of mouth to other customers who happen to be highly influenced by their opinions."

"Trust is the key to gain more profits". "Trust will increase the volume of work between the bank and the customer which will result in a more profitable relationship, and will ultimately maintain and build up the bank's market share. One far more benefit is that the bank reputation will be enhanced which will have a great impact on other customers and can attract other customers."

"We constantly ask our newly attracted customers about how they've heared about us, a good percentage of the answers is "family and friends"

"I am almost sure that many of our satisfied customers will talk about our bank to his family and friends, and we know that through asking customer."

"Sometimes we urge customers to do so, when the relationship between us and the customer gets personal, we ask them to recommend us to other people they know and many of the were capable of attracting a good number of other customers."

\section{Customer profitability}

Some of the respondents believe that all customers can be profitable; we just need to be patient to make out the best of these customers. As mentioned by one customer:

We believe that each and every customer can be profitable at a certain point of life; we are patient in our approach with unprofitable customers.

We study our customer accounts at a regular basis, when one customer becomes unprofitable (starts to develop a discrete relationship with the bank); we try to push this customer harder to use more of our services through cross selling and constant contact. We do not aim at losing our customers easily; instead we try to transform the unprofitable customers to become more profitable

If we were unable to transform them from unprofitable customer to be profitable, we apply some extra charges that can compensate for managing the unprofitable account, alternatively this may result in customer defection (losing unprofitable customer can have a positive impact on profitability).

Customer selection is one way of eliminating unprofitable customers, we study our prospect customers carefully then decide whether to engage in a relationship with them or not, we have different types of accounts that are highly customized. We try to choose the right customer for the right account and restrict the benefits that can be gained by some customers to the basic benefits, the customer will respond in one of two ways. Either he/she will try to become more engaged in order to get an account upgrade (and become more profitable) or he/she will leave the bank to become a customer elsewhere.

\section{Employee empowerment and special treatment}

Many of the respondents stressed that the intra-organizational environment should promote a culture of flexibility and that employees should be empowered to take decisions without always referring back to the management, they can discuss the terms of the service with the customers in order to deliver a more customized service.

"The bank should excel in quality to achieve the client satisfaction". "The means that bank should try to make all of its customers feel exceptional; however some customers are special and account for large percentage of the bank's profits. The bank needs to pay special attention to these customers; these customers should be kept satisfied and should receive preferable treatment."

However this kind of special treatment has some disadvantages

"One of the downsides of the differential treatment of customers is the risk that the bank may lose other customers trust if they perceive that they are not getting similar treatment to other customers."

"Some customers will find it unfair to treat customers differently, this kind of special treatment may be done thought a special branch exclusively catering for VIP's."

This is why many respondents stressed that all customers are unique and should receive special treatment.

"Preferable treatment for special customers does not mean in anyway that other customers should be neglected or mistreated. The bank has its own unique set of standards and rules about how to treat customers, but special customers have their standards to be compatible with their wants, needs and investments in our bank."

"Profitability is not the only variable that discriminate customers in terms of treatment they get, customers are 
naturally different and come from different backgrounds; there are personality and cultural differences. These should be taken into account and affect the nature of the relationship that the bank and the customer have."

\section{Drivers toward relational strategies}

The respondents mentioned a number of concepts essential for developing relational strategies with customer; these are the driving forces behind retaining customers for a long while. These drivers include the following:

Trust: "Trust is a central concept in building customer relationships; people will not enter a relationship with a bank if this bank is perceived as lacking trust."

"Trust makes the relationship between customers and employees more powerful and affects the quality of this relationship."

Satisfaction "Satisfaction is the most important thing in customer's retention process."

"Customer service plays an essential and most important role in customer satisfaction."

"Satisfaction is related directly with service providers' ability to provide services to customers quickly and efficiently which will increase both customer satisfaction and retention."

"Satisfaction will enhance the bank's ability to solve the problems that the customer is facing; if we were able to do so this will lead to trust."

Loyalty "Loyalty is a very important source of word of mouth; it is the loyal customers who usually try to convince others to become customers, they are a great customer attraction tool.

"Although not all of the satisfied customers are loyal, yet they constitute a large percentage of these customers."

Ethical profile of the bank is directly related with the quality of relationship.

"Relation between bank and his customers should be built on cooperation, trust and loyalty between each others, because customer will give to bank all his secrets about his money, investment and loans..... "

Commitment "Commitment reflects the degree of creditability of the bank and if bank have the creditability this will improve relations with the customer and make them recommended bank for others (family and friends)."

Closeness "Closeness enhances the mutual understanding." Because:

"Closeness decreases the distance between the client and the bank and enhances trust which will ultimately increase customer retention."

"Closeness to customers means more understanding of their needs, it is the way to keep customers satisfied and retained."

"Closeness can mean two things; geographical approximation which can be achieved through developing a network of branches and ATM machines in several locations and psychological closeness; to understand, care, and help customers."

Communication "The basis for mutual cooperation is the effective communication between the bank and its customers."

"Two way communications will enhance transparency and ultimately will affect customer trust."

Transparency "Transparency directly affects trust; we try to tell the customer every thing that he needs to know about his account and about the bank."

Confidentiality and privacy "Confidentiality is what produces trust, the customer should be $100 \%$ sure that his information will be kept secret and will not be shared with anyone else."

"Confidentiality: the confidentiality is very important and it is the main thing customer look at it."

Organizational culture "The bank should promote a culture of diversity; employees should have enough experience to deal with all types of customers. Training is vital; employees should develop their communication skills."

Customer acquisition cost "Customer acquisition costs can be especially high in a highly competitive industry, this is a why we try to retain customer."

Reputation "Reputation determines wither to deal with the bank or not."

"Customer retention has a direct effect on the banks image and reputation."

"The ability of the bank to build an image that promotes quality, credibility and customer care is what reputation 
is all about"

\section{Discussion of Findings}

This study found a number of factors that are critical in achieving customer retention. These include trust, satisfaction, commitment, loyalty, closeness, communication transparency, privacy, cost, reputation and organisational culture.

A considerable body of research has tested the main effect of satisfaction on retention and has generally found a significant positive effect of satisfaction and the findings of this study is consistent with previous literature.

However, some previous research has provided limited empirical insight into the impact of trust on customer retention (Ranaweera and Prabhu, 2003). However; This research confirms the expected positive effect of trust on retention. This is consistent with (Lee et al., 2011) who states that it is critical for organizations to develop and nurture consumer trust in order to build a long-term relationship.

Trust and commitment are two highly interrelated concepts; they both stimulate a relational bond between the supplier and the customer that facilitates the collaborations that reduces uncertainty and increases value for both parties (Gounaris, 2005).

Accordingly, customer satisfaction is a direct determinant of customer loyalty, which, in turn, is a central determinant of customer retention (Gerpott et al., 2001). An abundance of research shows that customer loyalty has important implications for customer satisfaction and that customer satisfaction positively affects customer loyalty (Jung and Yoon, 2013).

Closeness can be controversial in a commercial relationship. Bove and Johnson (2001) stresses that the term relationship closeness should only be used in a commercial setting when the relationship between a customer and service provider has gone beyond a commercial exchange and has developed into a communal (friendship) relationship. This close customer relationships can bring some disadvantages to service workers where some customers may take advantage of this friendship.

Marketing communications with existing customers and prospects plays an important role in their continued existence (Kumar, 2010). Interactive technologies allow customers to interact with each other and provide tools for communication and negotiation among buyers and sellers, and significantly enhance the customers' experience (Varadarajan et al., 2010). This is consistent with the results of this research which stresses that continuous two-way communication is critical for retaining customers and increasing the longitude of the buyer-seller relationships.

Murphy et al. (2007) stresses the important role that transparency plays in a relationships; relationships should occur with transparency of communication and action. Transparency is an important development in the field of marketing and is directly related to the ethical basis of relationship marketing. Transparency is reflected in the openness and clarity of a relationship and it is very important for relationship marketing to occur and flourish.

customer loyalty is strongly dependent on the customers' trust in the vendor (Enzmann and Schneider, 2005). Thus, if customers are convinced that vendors will not harm their privacy their loyalty may even increase. This is particularly important to attract privacy sensitive customers.

Switching barriers provide disincentives for the customer to leave to another organisation by making it costly for customers to switch (Cohen et al., 2007). High switching costs are an important factor binding the customer to the organisation. The customer continues to patronise the service provider even with relatively low levels of satisfaction because repurchasing is easier and more cost effective than searching for a new service provider (Curasi and Kennedy, 2002)

It is critical for a bank to manage its reputation since a favourable reputation contributes to customers' perceptions of the trustworthiness of a bank, which will ultimately increase customer retention (Liu and Wu, 2007).

There is a significant and positive association between marketing culture and customer retention. Firms with a strong marketing culture are perceived to be retaining customers at a better rate than competitors with a relatively weak marketing culture (Appiah-Adu et al., 2000).

\section{Conclusions}

The current study investigated the significant role that customer retention and relational approach can have on keeping Jordanian bank customers. The study findings showed that there are a number of predecessors to achieving longevity in a relationship that will finally lead to lessen the defection rates in banking industry. These 
antecedents include; trust, satisfaction, commitment, loyalty, closeness, communication transparency, privacy, cost, reputation and organisational culture. All of these antecedents are proposed to have a great deal of impact on customer retention.

This research also revealed a number of vital strategies and tactics used by banks to achieve customer retention. These include loyalty scheme programmes, developing product and service quality, continuous contact and two-way communication, developing the internal customers (human resources) through emphasizing the important role of internal marketing, and benchmarking with other banks to stay competitive.

The respondents mentioned two major benefits that a bank can get from retaining customers for a long while and that are closely related to achieving increased profitability. In one hand; customer retention help build and maintain customer base, customer base is critical for achieving market growth and market share and helps the bank in future planning and enhancing the competitive position of the bank. On the other hand, positive word of mouth and customers recommendations will result in referrals of friends and relatives which ultimately will positively impact the bank profits.

\section{Limitations and Future Research}

Although this study revealed a number of important precursors for achieving customer retention. It didn't show how these are related. Further study is needed to explain how these constructs are linked in order to develop a model of customer retention.

Another important issue is that these constructs although can be global across industries, some of them might be context sensitive. Also, there may be other factors that may have an impact in a different setting. A study of customer retention strategies across other industries might be needed to deepen the understanding of the nature of relationship formation.

\section{References}

Al-Shammari, M., \& Salimi, A. (1998). Modeling the operating efficiency of banks: a nonparametric methodology. Logistics Information Management, 11, 5-17. http://dx.doi.org/10.1108/09576059810202196

Ang, L., \& Buttle, F. (2006). Customer retention management processes: A quantitative study. European Journal of Marketing, 40, 83-99. http://dx.doi.org/10.1108/03090560610637329

Appiah-Adu, K., Fyall, A., \& Singh, S. (2000). Marketing culture and customer retention in the tourism industry. The Service Industries Journal, 20, 95-113. http://dx.doi.org/10.1080/02642060000000022

Association of Banks in Jordan. (2009). Development of the Jordanian Banking Sector (2000-2008).

Bove, L. L., \& Johnson, L. W. (2001). Customer relationships with service personnel: do we measure closeness, quality or strength? Journal of Business Research, 54, 189-197. http://dx.doi.org/10.1016/S0148-2963(00)00122-3

Cohen, D., Gan, C., Au Yong, H. H., \& Chong, E. (2007). CUSTOMER RETENTION BY BANKS IN NEW ZEALAND. Banks and Bank Systems, 2, 40-56.

Curasi, C. F., \& Kennedy, K. N. (2002). From prisoners to apostles: A typology of repeat buyers and loyal customers in service businesses. The Journal of Services Marketing, 16, 322-341. http://dx.doi.org/10.1108/08876040210433220

Danesh, S. N., Nasab, S. A., \& Kwek Choon, L. (2012). The Study of Customer Satisfaction, Customer Trust and Switching Barriers on Customer Retention in Malaysia Hypermarkets. International Journal of Business \& Manaigement, 7, 141-150. http://dx.doi.org/10.5539/ijbm.v7n7p141

Dwairi, M., Bhuian, S. N., \& Jurkus, A. (2007). Revisiting the pioneering market orientation model in an emerging economy. European Journal of Marketing, 41, 713-721. http://dx.doi.org/10.1108/03090560710752357

Enzmann, M., \& Schneider, M. (2005). Improving Customer Retention in E-Commerce through a Secure and Privacy-Enhanced Loyalty System. Information Systems Frontiers, 7, 359-370. http://dx.doi.org/10.1007/s10796-005-4808-2

Gerpott, T. J., Rams, W., \& Schindler, A. (2001). Customer retention, loyalty, and satisfaction in the German mobile cellular telecommunications market. Telecommunications Policy, 25, 249-269. http://dx.doi.org/10.1016/S0308-5961(00)00097-5

Gounaris, S. P. (2005). Trust and commitment influences on customer retention: insights from 
business-to-business services. Journal of Business Research, 58, 126-140. http://dx.doi.org/10.1016/S0148-2963(03)00122-X

Harrison, T., \& Ansell, J. (2002). Customer retention in the insurance industry: Using survival analysis to predict cross-selling opportunities. Journal of Financial Services Marketing, 6, 229-239. http://dx.doi.org/10.1057/palgrave.fsm.4770054

Hidalgo, P., Manzur, E., Olavarrieta, S., \& Farã-As, P. (2008). Customer retention and price matching: The AFPs case. Journal of Business Research, 61, 691-696. http://dx.doi.org/10.1016/j.jbusres.2007.06.046

Jung, H. S., \& Yoon, H. H. (2013). Do employees' satisfied customers respond with an satisfactory relationship? The effects of employees' satisfaction on customers' satisfaction and loyalty in a family restaurant. International Journal of Hospitality Management, 34, 1-8. http://dx.doi.org/10.1016/j.jhm.2013.02.003

Kumar, V. (2010). A Customer Lifetime Value-Based Approach to Marketing in the Multichannel, Multimedia Retailing Environment. Journal of Interactive Marketing, 24, 71-85. http://dx.doi.org/10.1016/j.intmar.2010.02.008

Lee-Kelley, L., Davies, S., \& Kangis, P. (2002). Service quality for customer retention in the UK steel industry: Old dogs and new tricks? European Business Review, 14, 276-276. http://dx.doi.org/10.1108/09555340210434465

Lee, K. C., Chung, N., \& Lee, S. (2011). Exploring the influence of personal schema on trust transfer and switching costs in brick-and-click bookstores. Information \& Management, 48, 364-370. http://dx.doi.org/10.1016/j.im.2011.09.002

Liu, T. C., \& Wu, L. W. (2007). Customer retention and cross-buying in the banking industry: An integration of service attributes, satisfaction and trust. Journal of Financial Services Marketing, 12, 132-145. http://dx.doi.org/10.1057/palgrave.fsm.4760067

Murphy, P. E., Laczniak, G. R., \& Wood, G. (2007). An ethical basis for relationship marketing: a virtue ethics perspective. European Journal of Marketing, 41, 37-57. http://dx.doi.org/10.1108/03090560710718102

PAL, P. (2011). Customer Retention through Service Recovery. International Journal of Research in Commerce and Management, 2, 131-134.

Ranaweera, C., \& Prabhu, J. (2003). The influence of satisfaction, trust and switching barriers on customer retention in a continuous purchasing setting. International Journal of Service Industry Management, 14, 374-395. http://dx.doi.org/10.1108/09564230310489231

Siam, A. Z. (2007). Effects of Collateral Pledges in Reducing Credit Risks -Confronting Banks in Jordan, as Lending Institutions. Journal of Social Sciences, 3, 134-137. http://dx.doi.org/10.3844/jssp.2007.134.137

Varadarajan, R., Srinivasan, R., Vadakkepatt, G. G., Yadav, M. S., Pavlou, P. A., Krishnamurthy, S., \& Krause, T. (2010). Interactive Technologies and Retailing Strategy: A Review, Conceptual Framework and Future Research Directions. Journal of Interactive Marketing, 24, 96-110. http://dx.doi.org/10.1016/j.intmar.2010.02.004

Weinstein, A. (2002). Customer-specific strategies--Customer retention: A usage segmentation and customer value approach. Journal of Targeting, Measurement and Analysis for Marketing, 10, 259-268. http://dx.doi.org/10.1057/palgrave.jt.5740051

\section{Copyrights}

Copyright for this article is retained by the author(s), with first publication rights granted to the journal.

This is an open-access article distributed under the terms and conditions of the Creative Commons Attribution license (http://creativecommons.org/licenses/by/3.0/). 